\title{
Reseña de Fray Toribio de Benavente, Motolinía, Historia de la indios de la Nueva España, ed. Mercedes Serna y Bernat Castany, Madrid, Real Academia Española/Centro para la Edición de los Clásicos Españoles, 2014, 439 pp., ISBN 978-84-617-0715-74
}

\section{Blanca Oteiza Pérez}

GRISO-Universidad de Navarra

ESPAÑA

boteiza@unav.es

[Hipogrifo, (issn: 2328-1308), 4.1, 2016, pp. 303-307]

Recibido: 05-02-2016 / Aceptado: 04-03-2016

DOI: http://dx.doi.org/10.13035/H.2016.04.01.22

La importante Historia de Fray Toribio Motolinía ('el pobrecito', en lengua de indios) dispone con este volumen de una completa edición, acompañada de un útil estudio y un aparato de notas que aporta relevante información para facilitar la lectura y entendimiento de uno de los textos más notables relativos al Nuevo Mundo, en este caso a la Nueva España.

El excelente estudio preliminar trata la biografía de Motolinía, que llega a la Nueva España en junio de 1524, con otro grupo de frailes franciscanos capitaneados por Fray Martín de Valencia -al que dedicará en la parte tercera de la Historia una biografía específica-. Motolinía debió de redactar en Tlaxcala la mayor parte de su Historia y otros textos, no conservados, como el que llamó Baudot Libro perdido, del que quizá la Historia sea una especie de resumen. De esos textos merecen especial atención algunas cartas escritas contra Las Casas, cuya actividad y alegatos radicales parecieron a Motolinía parciales, injustos y contraproducentes.

Buena parte del estudio preliminar se dedica, como es natural, al propio texto editado, contextualizando y ofreciendo autorizadamente el estado de la cuestión sobre muchos temas involucrados.

Motolinía se ocupa en su Historia de costumbres, paisajes, ritos, vestidos, descripciones de ciudades... En su evocación de la Nueva España y las circunstancias 
que recoge en su libro se ofrece una visión compleja de la Conquista: por un lado se plantea una dura crítica contra los excesos de los codiciosos que destruyen la sociedad de los indios; por otra reivindica el valor de la cristianización, que acaba con diabólicos sacrificios humanos y libera muchos esclavos (al tiempo que encomenderos sin escrúpulos esclavizan a muchos indios).

Los escritos de Fray Toribio, no publicados hasta el siglo XIX, tienen una complicada situación textual, que se analiza con autoridad en este prólogo. Cuestión de especial interés para los estudiosos de la literatura es la de las representaciones teatrales en las fiestas de Tlaxcala, como las del Corpus de 1539, donde Motolinía menciona varios autos dramáticos - conquista de Jerusalén, auto de Adán y Eva...-, alguno de los cuales podría ser suyo (aunque nada seguro hay sobre la autoría de esas piezas, cuyos textos por otra parte no se conservan).

En su conjunto la Historia

relata la historia y costumbres de los pueblos de la Nueva España antes de la conquista y las vicisitudes ocurridas durante la conversión y proceso de evangelización de los indios, concretado este último en el testimonio personal de nuestro autor y de la orden franciscana (p. 43*).

El valor etnográfico y antropológico de la Historia de Motolinía es evidente. A este respecto hubiera sido de agradecer quizá que los editores concretaran con más nitidez algunas observaciones sobre la perspectiva del narrador y su influencia en lo narrado, por ejemplo en el asunto del canibalismo, donde parecen fluctuar entre la aseveración de tal práctica y la duda, en cuanto se trata de un tema tradicional que aparece en muchas descripciones de pueblos extraños desde la antigüedad. Pero es de suponer que los especialistas en historia indiana sepan si se practicaba o no la antropofagia: y en ese sentido holgaría alguna nota como la complementaria de pp. 329-330 que aporta documentación sobre las leyendas de antropófagos, etc., que en este caso más que informar podría desviar la información fidedigna.

Algo semejante podría decirse a propósito de algunas otras afirmaciones como las de p. 47* cuando se apunta que «En muchas ocasiones, las víctimas de estos sacrificios [de los aztecas] [...] eran voluntarias, ya que la muerte en la guerra y en el sacrificio eran consideradas las más nobles maneras de morir». No encuentro en la Historia de Motolinía esa 'voluntariedad', sino su explícita negativa: los sacrificios voluntarios son los penitenciales de horadarse orejas o espinillas, o lengua, etc., pero los que implican la muerte, decapitaciones o desmembramientos se realizan siempre sobre cautivos o esclavos:

nadie se piense que ninguno de los que sacrificaban matándolos y sacándoles el corazón o cualquiera otra muerte, que no era de su propia voluntad, sino por fuerza, y sintiendo muy sentida la muerte y su espantoso dolor. Los otros sacrificios de sacarse sangre de las orejas o lengua o de otras partes, esos eran 
voluntarios casi siempre [...] todos los sacrificados o eran esclavos o tomados en la guerra (p. 46) ${ }^{1}$.

Son muy valiosas las páginas dedicadas a las fuentes, influencia, y finalidad de la obra. Con muy buen acierto se comentan los posibles varios objetivos que los estudiosos han advertido en la Historia, desde la defensa de la evangelización franciscana, hasta el testimonio personal. Muy dudoso ven, con acierto a mi juicio, el propósito de evitar la aprobación de las Leyes Nuevas. Que Motolinía se enfrente a Las Casas no significa que no apruebe las disposiciones de las Leyes protectoras de los indios. Toda la Historia está llena de requisitorias contra las injusticias que sufren los indígenas, de modo que interpretarla como apología de los tributos (según hace Surtz de manera absurda, ver p. 69*) resulta, ciertamente, inadmisible.

Al revisar los aspectos literarios destacan los editores la sencillez estilística, que relacionan con la idea de pobreza de los franciscanos, sencillez no reñida con la utilización de recursos como formas populares, anécdotas y cuentecillos, y hasta rasgos de humor para atraer el interés del lector.

Muy documentada es la historia del texto, y abundantes en información complementaria las notas finales.

La fijación textual es muy cuidada: solo he advertido un par de erratas y dos o tres casos de puntuación discutible².

El aparato de notas se caracteriza por su economía y general eficacia, con unos cuantos casos que pudieran matizarse o completarse. Como sugerencias provenientes del interés que suscita el texto y su tratamiento erudito, valgan las que propongo a continuación.

En p. 24 «afrontados» («afrontados y desterrados») más que 'el que está en peligro' sería 'afrentados, objetos de afrentas, insultos y agravios'.

En p. 44 menciona Motolinía dos dioses de la guerra hermanos, y la nota solo aclara la alusión a Huitzilopochtli; el hermano de este debe de ser Tezcalipoca, dios de los infiernos, hermano del antecitado dios de la guerra.

pp. 44-45 el texto imprime «tieso», pero se anota la forma «teso» - como si fuera esta la que figura en el texto-, 'tieso'; parece que ha habido un salto de formas en la composición. No creo que haga falta apelar a la interpretación de O'Gorman que lo hace derivar del verbo tesar 'tensar dos cabos', ya que el étimo tensum (>teso) significa 'extendido, tenso, tirante', que describe perfectamente la posición de los sacrificados.

1. Es posible que los editores interpreten mal la negación expletiva («nadie se piense... que no era de su propia voluntad»), es decir 'nadie piense que era voluntariamente'.

2. Casos que no entorpecen la comprensión del texto: valga el ejemplo de la p. 3: «la razón que le hace hombre capaz y merecedor de la gloria, y le distingue y aparta de los brutos animales», que supone una oración de relativo especificativa, cuando se trata de una explicativa, ya que todos los hombres tienen razón que los hace capaces de gloria: puntúese, «la razón que le hace hombre, capaz y merecedor de la gloria, y le distingue y aparta de los brutos animales». 
p. 50 la pelota de viento no es exactamente un balón o pelota grande; la denominación no se refiere al tamaño, sino al hecho de que es hueca, esto es, no rellena de borra, como eran otras (Autoridades define a la de viento: «La bola de cuero que se deja hueca, y con una vejiga, y se carga de aire dentro»).

p. 55 las lenguas harpadas no son las que tienen dientecillos parecidos a una sierra, sino las bífidas, rasgadas, con dos puntas (el texto se refiere a los penitentes aztecas que se rajan la lengua).

p. 57 las varas de tirar se interpretan como medidas de longitud y tirar 'trazar rayas'; pero significan simplemente especie de flechas (ver pp. 62,65, 101).

p. 68 la cepa que sirve de cimiento a un templo no es un hoyo, como afirma la nota, sino parte de un pilar: nótese que se habla de la elevación de la obra («en lo más eminente de ese patio... Quedaba la cepa en lo alto de treinta y cuatro o treinta y cionco brazas»).

p. 77 el pasaje «más petaca y hato tienen que arrancar a una recua» no se entiende; dispóngase: «más petaca y hato tienen que arrancara una recua» 0 «arrancará una recua», 'más posesiones que las que puede arrastrar o cargar una recua'.

p. 172 convendría anotar la referencia a los cuerpos muertos que echa la tierra de sí; porque es adaptación de la creencia de que el mar arrojaba a tierra a los ahogados después de tres días, como recuerda, entre otros Quevedo en El mundo por de dentro:

Muchos hay buenos escribanos y alguaciles muchos, pero de sí el oficio es con los buenos como la mar con los muertos, que no los consiente y dentro de tres días los echa a la orilla... (p. 297) ${ }^{3}$

p. 176 el pasaje «como los ángeles que señalan con el tau a los gimientes y dolientes», se anota: «Alusión a Apocalipsis, 7, 3-8, donde los ángeles señalan en la frente (no se dice con una cruz), con el objetivo de protegerlos, a ciento cuarenta y cuatro mil...». Pero el texto no se refiere a Apocalipsis, sino a Ezequiel, 9, 3-6, donde los ángeles señalan con una tau a los que gimen por las abominaciones: «Yahvéh llamó entonces al hombre vestido de lino que tenía la cartera de escribano a la cintura, y le dijo: Recorre la ciudad, Jerusalén, y marca una tau en la frente de los hombres que gimen y lloran por todas las abominaciones que se cometen en ella».

p. 207 la referencia a Egipto («esta tierra fue otra Egipto en idolatrías») no tiene que ver con la esclavitud del pueblo de Israel (sobra entonces la nota complementaria correspondiente a esta 4 de p. 207), sino simplemente funciona como ejemplo de idolatría, ya que los egipcios eran idólatras.

p. 223 quizá conviniera anotar la expresión «señores de salva», los muy importantes a los que se hace la salva de la comida (probar la comida para comprobar que no tiene veneno): comp. Autoridades: «Salva. La prueba que se hace de la comida o bebida cuando se administra a los reyes, para asegurar que no hay peligro

3. Ver Francisco de Quevedo, Los sueños, ed. Ignacio Arellano, Madrid, Cátedra, 1999. 
alguno en ellas. En España la hace la persona de más distinción que sirve a la mesa. [...] Deben los señores de salva tener gran cuidado en que la salva de la comida y bebida se haga no solo por ceremonia... sino que quien la hace coma, y beba».

Pocas observaciones, como se ve, para un texto que se ofrece anotado con cuidado y solvencia.

Hay índice de topónimos y antropónimos, pero se hubiera agradecido también un índice de notas.

En conjunto una valiosa aportación a los estudios de crónicas e historia de Indias que merece el agradecimiento del lector. 
